medRxiv preprint doi: https://doi.org/10.1101/2021.08.04.21260420; this version posted August 6, 2021. The copyright holder for this preprint (which was not certified by peer review) is the author/funder, who has granted medRxiv a license to display the preprint in perpetuity.

All rights reserved. No reuse allowed without permission.

\title{
Helmet noninvasive ventilation for COVID-19 patients "Helmet-COVID": study protocol for a multicenter randomized controlled trial
}

\author{
Yaseen Arabi, MD FCCP, FCCM, ATSF [YA]
}

Intensive Care Department, Ministry of National Guard Health Affairs, Riyadh, Saudi Arabia

King Abdullah International Medical Research Center

King Saud Bin Abdulaziz University for Health Sciences, Riyadh, Saudi Arabia

yaseenarabi@yahoo.com

\author{
Haytham Tlayjeh, MD [HT] \\ Intensive Care Department, Ministry of National Guard Health Affairs, Riyadh, Saudi Arabia \\ King Abdullah International Medical Research Center \\ King Saud Bin Abdulaziz University for Health Sciences, Riyadh, Saudi Arabia \\ tlayjehh@ngha.med.sa
}

\section{Sara Aldekhyl, MBBS [SD]}

College of Medicine, King Saud Bin Abdulaziz University for Health Sciences, Riyadh, Saudi Arabia

King Abdullah International Medical Research Center

Ministry of National Guard Health Affairs, Riyadh, Saudi Arabia

DakheelS@NGHA.MED.SA

\author{
Hasan M Al-Dorzi, MD [HD] \\ Intensive Care Department, Ministry of National Guard Health Affairs, Riyadh, Saudi Arabia \\ King Abdullah International Medical Research Center \\ King Saud Bin Abdulaziz University for Health Sciences, Riyadh, Saudi Arabia \\ aldorzin@yahoo.com
}

\section{Sheryl Ann Abdukahil, RN [SA]}

Intensive Care Department, Ministry of National Guard Health Affairs, Riyadh, Saudi Arabia

King Abdullah International Medical Research Center

King Saud Bin Abdulaziz University for Health Sciences, Riyadh, Saudi Arabia

abdukahil.sheryl@gmail.com

Mohammad Khulaif Al Harbi, MD, FRCPC [MH]

Department of Anesthesia, Ministry of National Guard Health Affairs, Riyadh, Saudi Arabia

King Abdullah International Medical Research Center

College of Medicine, King Saud Bin Abdulaziz University for Health Sciences, Riyadh, Saudi

Arabia

HarbiMK@NGHA.MED.SA

\section{Husain Al Haji, RRT [HH]}

Respiratory Services Department, Ministry of National Guard Health Affairs, Riyadh, Saudi

Arabia

King Abdullah International Medical Research Center

King Saud Bin Abdulaziz University for Health Sciences, Riyadh, Saudi Arabia

HajiH@NGHA.MED.SA

\section{Mohammed Al Mutairi, RRT [MM]}

Respiratory Services Department, Ministry of National Guard Health Affairs, Riyadh, Saudi Arabia

King Abdullah International Medical Research Center

King Saud Bin Abdulaziz University for Health Sciences, Riyadh, Saudi Arabia

MutairyMM@NGHA.MED.SA 
medRxiv preprint doi: https://doi.org/10.1101/2021.08.04.21260420; this version posted August 6, 2021. The copyright holder for this preprint (which was not certified by peer review) is the author/funder, who has granted medRxiv a license to display the preprint in perpetuity.

All rights reserved. No reuse allowed without permission.

Omar Al Zumai, RRT [OZ]

Respiratory Services Department, Ministry of National Guard Health Affairs, Riyadh, Saudi Arabia

King Abdullah International Medical Research Center

King Saud Bin Abdulaziz University for Health Sciences, Riyadh, Saudi Arabia

ZumaiO@NGHA.MED.SA

Eman Al Qasim, RN, MSN [EQ]

Research Office, King Abdullah International Medical Research Center

King Saud Bin Abdulaziz University for Health Sciences, Riyadh, Saudi Arabia

Ministry of National Guard Health Affairs, Riyadh, Saudi Arabia

Eman77al-qasim@hotmail.com

\title{
Wedyan Al Wehaibi [WW]
}

Intensive Care Department, Ministry of National Guard Health Affairs, Riyadh, Saudi Arabia King Abdullah International Medical Research Center

King Saud Bin Abdulaziz University for Health Sciences, Riyadh, Saudi Arabia

wedyan.mohammed@outlook.com

\section{Saad Al Qahtani, MD, MMED, MAHA, FRCPC [SQ]}

Intensive Care Department, Ministry of National Guard Health Affairs, Riyadh, Saudi Arabia King Abdullah International Medical Research Center

King Saud Bin Abdulaziz University for Health Sciences, Riyadh, Saudi Arabia

mcmasterer@hotmail.com

\section{Fahad Al-Hameed, MD, FRCPC [FH]}

Intensive Care Department, Ministry of National Guard Health Affairs, Jeddah, Saudi Arabia King Abdullah International Medical Research Center

King Saud Bin Abdulaziz University for Health Sciences, Jeddah, Saudi Arabia

HameedF@ngha.med.sa

Jamal Chalabi, MD [JC]

Intensive Care Department, Ministry of National Guard Health Affairs, Al Ahsa, Saudi Arabia King Abdullah International Medical Research Center

King Saud Bin Abdulaziz University for Health Sciences, Al Ahsa, Saudi Arabia

ChalabiJA@NGHA.MED.SA

Mohammed Alshahrani, MBBS , SSC-EM , ArEM, FCCM [MS]

Department of Emergency and Critical Care

King Fahad Hospital of the University

University of Dammam

Al Khobar, Kingdom of Saudi Arabia

msshahrani@uod.edu.sa

\author{
Abdulrahman Alharthy, MD [AH] \\ Intensive Care Department \\ King Saud Medical City \\ Riyadh, Saudi Arabia \\ a_almshal@hotmail.com
}

\author{
Ahmed Mady, MBBCH, MSc, MD,S-FCCM,FCCP [AM] \\ Intensive Care Department \\ King Saud Medical City \\ Riyadh, Saudi Arabia \\ College of Medicine \\ Tanta University, Egypt \\ afmady@hotmail.com
}




\author{
Abdulhadi Bin Eshaq, MD [AE] \\ Intensive Care Department \\ King Khalid Hospital, Najran \\ drbineshaq@gmail.com
}

Ali Al Bshabshe, MD, SSCIM, JBIM, ArBIM, MRCP(UK),EDIC,CNSC [AB]

Department of Critical Care Medicine

King Khalid University, Aseer Central Hospital

Abha, Kingdom of Saudi Arabia

albshabshe@yahoo.com

Zohair Al Aseri, MD, FCEM, FRCPC [ZA]

Emergency and Intensive Care Departments

College of Medicine

King Saud University

Riyadh, Saudi Arabia

zohairalaseri@yahoo.com

Zainab AI Duhailib, MBBS, EDIC, MSc [ZD]

Adult Critical Care Department

King Faisal Specialist Hospital \& Research Center

Riyadh, Saudi Arabia

zalduhailib65@kfshrc.edu.sa

\title{
Ayman Kharaba MD, ABIM,FRCPC [AK]
}

Pulmonary \& Critical Care Departments, King Fahad Hospital Madinah

Critical Care Units- Madinah Region, Ministry of Health

a7yman@hotmail.com

Rakan Alqahtani, MD [RQ]

Department of Critical Care,

King Khalid University Hospital

King Saud University, Riyadh, Saudi Arabia.

arakan@KSU.EDU.SA

Adnan Al Ghamdi, MD [AG]

Department of Intensive Care Services

Prince Sultan Military Medical City

Riyadh, Saudi Arabia

sbb1971@hotmail.com

\section{Ali Altalag, MD [AT]}

Department of Intensive Care Services

Prince Sultan Military Medical City, Riyadh, Saudi Arabia

drtalag@yahoo.com

Khalid Alghamdi, MD [KG]

Intensive Care Department

King Faisal Specialist Hospital \& Research Center, Jeddah, Saudi Arabia

kal-ghamdi@kfshrc.edu.sa

Mohammed Almaani, MD,SSC- Em, ArBEM, UWO FCCM [MA]

Department of Pulmonary \& Critical Care Medicine

King Fahad Medical City

King Saud Bin Abdulaziz University for Health Sciences

Riyadh, Saudi Arabia 
malmaani@kfmc.med.sa

\author{
Haifa Algethamy, MD [HG] \\ Department of Anesthesia and Critical Care \\ King Abdulaziz University \\ King Abdulaziz University Hospital \\ Jeddah, Saudi Arabia \\ halgethamy2020@gmail.com
}

\begin{abstract}
Ahmad Al Aqeily, RRT [AA]
Respiratory Services Department, Ministry of National Guard Health Affairs, Riyadh, Saudi Arabia

King Abdullah International Medical Research Center

King Saud Bin Abdulaziz University for Health Sciences, Riyadh, Saudi Arabia

AqeilA@NGHA.MED.SA
\end{abstract}

\title{
Faisal Al Baseet, RRT [FB]
}

Respiratory Services Department, Ministry of National Guard Health Affairs, Riyadh, Saudi Arabia

King Abdullah International Medical Research Center

King Saud Bin Abdulaziz University for Health Sciences, Riyadh, Saudi Arabia

albaseetfa@NGHA.MED.SA

\section{Hashem Al Samannoudi, RRT [HS] \\ Respiratory Services Department, Ministry of National Guard Health Affairs, Riyadh, Saudi Arabia \\ King Abdullah International Medical Research Center \\ King Saud Bin Abdulaziz University for Health Sciences, Riyadh, Saudi Arabia \\ SamannoudiHa@NGHA.MED.SA}

\section{Mohammed Al Obaidi, RRT [MO]}

Respiratory Services Department, Ministry of National Guard Health Affairs, Riyadh, Saudi Arabia

King Abdullah International Medical Research Center

King Saud Bin Abdulaziz University for Health Sciences, Riyadh, Saudi Arabia

alobaidimo@NGHA.MED.SA

Yassin Ismaiel, RRT [YI]

Respiratory Services Department, Ministry of National Guard Health Affairs, Riyadh, Saudi Arabia

King Abdullah International Medical Research Center

King Saud Bin Abdulaziz University for Health Sciences, Riyadh, Saudi Arabia

IsmaeilY@NGHA.MED.SA

\section{Abdulrahman A Al-Fares, MBChB, MRCP, ABIM, FRCPC [AF]}

Department of Anesthesia, Critical Care Medicine and Pain Medicine

Al-Amiri Hospital, Ministry of Health, Kuwait

abdulrahman.alfares@gmail.com

\section{Corresponding author}

\section{Yaseen Arabi, MD FCCP, FCCM, ATSF [YA]}

(ORCID: 0000-0001-5735-6241)

Intensive Care Department, Ministry of National Guard Health Affairs, Riyadh, Saudi Arabia

King Abdullah International Medical Research Center

King Saud Bin Abdulaziz University for Health Sciences, Riyadh, Saudi Arabia

yaseenarabi@yahoo.com 
medRxiv preprint doi: https://doi.org/10.1101/2021.08.04.21260420; this version posted August 6, 2021. The copyright holder for this preprint (which was not certified by peer review) is the author/funder, who has granted medRxiv a license to display the preprint in perpetuity.

All rights reserved. No reuse allowed without permission. 


\begin{abstract}
Introduction

Noninvasive ventilation delivered by helmet is has been used for respiratory support of patients with acute hypoxemic respiratory failure due to COVID-19 pneumonia. The aim of this study is to compare helmet noninvasive ventilation with usual care versus usual care alone to reduce the mortality.
\end{abstract}

\title{
Methods and analysis
}

This is a multicenter, pragmatic, parallel, randomized controlled trial that compares helmet noninvasive ventilation with usual care to usual care alone in 1:1 ratio. A total of 320 patients will be enrolled in this study. The primary outcome is 28 -day all-cause mortality. The primary outcome will be compared between the two study groups in the intention-to-treat and perprotocol cohorts. An interim analysis will be conducted for both safety and effectiveness.

\section{Ethics and dissemination}

Approvals are obtained from the Institutional Review Boards (IRBs) of each participating institution. Our findings will be published in peer-review journals and presented at relevant conferences and meetings.

Trial registration number NCT04477668 registered on July 20, 2020

\section{Article Summary}

\section{Strengths and limitations of this study}

- This trial compares helmet NIV to usual care for respiratory support of patients with acute hypoxemic respiratory failure due to COVID-19 pneumonia.

- The trial is a multi-center, pragmatic, parallel randomized controlled trial.

- The main limitation is the unblinded design due to the nature of the intervention. 


\section{Introduction}

The novel severe acute respiratory syndrome coronavirus 2 (SARS-CoV-2) has led to a pandemic resulting in over 181 million cases and approximately 3.9 million fatalities as of June 29, 2021. ${ }^{1}$ The resulting Coronavirus Disease 2019 (COVID-19) leads to severe pneumonia and acute respiratory distress syndrome (ARDS) among other organ injury. ${ }^{2}$ ARDS may occur in up to $5 \%$ of infected patients. ${ }^{3-5}$ Early in the pandemic, invasive mechanical ventilation was widely used because of concerns about noninvasive ventilation safety and efficacy. However, noninvasive ventilation (NIV) use increased with time, including mask NIV and helmet NIV.

NIV has been shown to be physiologic benefits in patients with acute hypoxemic respiratory failure (AHRF) secondary to pulmonary edema, atelectasis, or pneumonia. ${ }^{6}$ It has been shown to improve arterial oxygenation by increasing functional residual capacity, shifting the tidal volume to a more compliant part of the pressure-volume curve, thus reducing both the work of breathing and the risk of tidal opening and closure of the airways. ${ }^{7} \mathrm{NIV}$ is commonly provided through nasal or oro-nasal interfaces. The resulting aerosol generation may increase the risk of transmission of pathogens to healthcare providers, raising concerns about the use of NIV in patients with viral pneumonia. ${ }^{8}$ Helmet NIV has been used for AHRF including patients with COVID-19 pneumonia. The helmet surrounds the patient's entire head to provide positive pressure and supply oxygen and is sealed with a soft, airtight collar that wraps around the neck. Due to this design, it has advantages over the nasal and oronasal interfaces. These include less air leaks, no skin or nasal bridge skin injuries, no eye irritation, fitting for different facial contours, ${ }^{9}$ and hypothetically less dissemination of aerosols in the environment. However, helmet interface may be associated with increase in dead space (especially if the settings are not used appropriately), claustrophobia, discomfort, and difficulty in access for suction and feeding. 
Evaluation of helmet NIV as a respiratory support modality started more than two decades ago. ${ }^{10}$ Helmet NIV has been investigated as a treatment for different forms of AHRF in adults in various settings, such as pre-hospital ambulance, emergency department and ICU. ${ }^{71-15}$ However, earlier clinical studies are relatively scarce and mostly small in size, and often used improvement in oxygenation and intubation rate as primary outcomes. ${ }^{6}$

However, the evidence on helmet NIV for AHRF is growing. A systematic review of randomized controlled trials (RCTs) and observational studies published before June 2016 found 11 studies involving 621 patients. ${ }^{16}$ Compared with controls, the use of the helmet was associated with lower hospital mortality, intubation rate, and complications. ${ }^{16}$ Moreover, there was no significant difference in gas exchange and ICU stay. ${ }^{16} \mathrm{~A}$ meta-analysis of four RCTs (377 patients) showed that helmet NIV significantly increased the ratio of arterial oxygen partial pressure to fraction of inspired oxygen $\left(\mathrm{PaO}_{2} / \mathrm{FiO}_{2}\right)$ and decreased arterial carbon dioxide levels, intubation rate and in-hospital mortality compared to standard oxygen therapy. ${ }^{17}$ In a more recent systematic review and network meta-analysis that included 25 studies (published up to April 2020) and 3804 patients with AHRF, mortality and intubation rate were lower with helmet NIV compared to standard oxygen by more than $50 \%$, while the effect of mask NIV and high-flow nasal oxygen were modest compared to standard oxygen. ${ }^{18}$ Helmet NIV was superior to both mask NIV and high-flow nasal oxygen, while mask NIV and high-flow nasal oxygen were not different in their effects on mortality and intubation rate. ${ }^{18}$ One study reported the cost-effectiveness of helmet NIV compared to mask NIV. ${ }^{19}$

Data on helmet NIV in AHRF related to COVID-19 are emerging. A recent RCT conducted in 4 Italian ICUs on patients with COVID-19 and moderate to severe AHRF found that treatment with helmet NIV did not result in significantly fewer days of respiratory support at 28 days from randomization (primary outcome) as compared with high-flow nasal oxygen alone (mean difference 2 days, $95 \% \mathrm{Cl},-2$ to $6, p=0.26$ ).${ }^{20}$ Nevertheless, the intubation rate 
was significantly lower in the helmet NIV group compared to the high-flow nasal oxygen group (30\% vs $51 \%$; $p=0.03) .{ }^{20}$ Additionally, the median number of days free of invasive mechanical ventilation within 28 days was significantly higher in the helmet NIV group than in the high-flow nasal oxygen group (28 versus 25 days; mean difference, 3 days; $95 \% \mathrm{Cl}, 0$ 7 ; $\square \square=\square 0.04) .{ }^{20}$ The hospital mortality was $24 \%$ in the helmet NIV group and $25 \%$ in the high-flow nasal oxygen group. ${ }^{20}$

As the efficacy of helmet NIV to improve outcomes in severe AHRF due to COVID-19 pneumonia has not been clearly established, the aim of this study is to compare helmet NIV with usual care versus usual care alone to reduce 28-day all-cause mortality. We hypothesize that helmet NIV will reduce 28-day all-cause mortality in patients with suspected or confirmed severe COVID-19 pneumonia and AHRF.

\section{Methods and analysis}

\section{Trial design}

This is an investigator-initiated, pragmatic parallel RCT that will compare helmet NIV with usual care to usual care alone in 1:1 ratio in patients with suspected or confirmed COVID-19 pneumonia and AHRF. Randomization is performed using a computer-generated schedule using variable block sizes ( 4 or 6 ) and is stratified by site. The trial is sponsored by King Abdullah International Medical Research Center, Riyadh, Saudi Arabia, has been registered with ClinicalTrials.gov (NCT04477668) and is conducted across multiple centers in Saudi Arabia. Training and in-service education on helmet NIV use as well as on protocol implementation are provided to all participating centers. The competency of the bedside respiratory therapists is supervised by experienced respiratory care supervisors and intensivists. 
medRxiv preprint doi: https://doi.org/10.1101/2021.08.04.21260420; this version posted August 6, 2021. The copyright holder for this preprint (which was not certified by peer review) is the author/funder, who has granted medRxiv a license to display the preprint in perpetuity.

All rights reserved. No reuse allowed without permission.

\section{Sample size}

In a large observation study of patients with AHRF and ARDS, hospital mortality was $34.9 \%$ (95\% CI, 31.4-38.5\%) for patients with mild ARDS, $40.3 \%$ (95\% Cl, 37.4\%-43.3\%) for those with moderate ARDS, and $46.1 \%(95 \% \mathrm{Cl}, 41.9 \%-50.4 \%)$ for those with severe ARDS. ${ }^{21} \mathrm{~A}$ systematic review found an overall pooled mortality estimate among 10,815 patients with ARDS due to COVID-19 to be $39 \%$ (95\% CI: $23-56 \%) .{ }^{22}$ Considering a mortality rate of $40 \%$ in patients with COVID-19 pneumonia and moderate to severe ARDS treated with usual care, we calculated that enrollment of 304 patients (152 in each group) would provide the study with $80 \%$ power to demonstrate an absolute difference of $15 \%$ in the primary outcome between the usual care group and helmet NIV group at a two-sided alpha level of 0.05 . To account for $5 \%$ loss to follow-up, the total number of patients required for the trial is 320 patients.

\section{Participant eligibility}

The trial will enroll ICU patients with suspected ${ }^{24}$ or confirmed COVID-19 pneumonia who have AHRF. Detailed inclusion and exclusion criteria can be found in Table 1.

\section{Informed consent}

Informed consent will be obtained from the potential trial participants or their surrogate decision makers. A hybrid model of consent will be used where a priori consent is obtained if possible, otherwise delayed consent model will be obtained as per local approvals. The first patient was enrolled in February 2021. As of June 29, 2021, a total of 199 patients were enrolled from 5 sites. There are several sites that are processing IRB and regulatory approvals. 
medRxiv preprint doi: https://doi.org/10.1101/2021.08.04.21260420; this version posted August 6, 2021. The copyright holder for this preprint (which was not certified by peer review) is the author/funder, who has granted medRxiv a license to display the preprint in perpetuity.

All rights reserved. No reuse allowed without permission.

\section{Patient and public involvement}

There was no patient or public involvement in the conception, design or conduct of the study, or the writing or editing of this paper. However, patient comfort and experience as well as compliance to the intervention were taken in to consideration and data on these are collected.

\section{Trial interventions}

\section{Helmet group}

A helmet (Subsalve, USA or its equivalent), which is made of transparent latex-free polyvinyl chloride, will be applied to patients randomized to the intervention group as per the study protocol which considers the manufacturer instructions. It will be immediately connected to an ICU ventilator in pressure support (PS) mode with positive end-expiratory pressure (PEEP) using a conventional respiratory circuit joining two port sites to allow inspiratory and expiratory flow. The starting settings is PS of $8-10 \mathrm{~cm} \mathrm{H} 2 \mathrm{O}$, PEEP of $10 \mathrm{cmH} 2 \mathrm{O}$ with $\mathrm{FiO}_{2}$ of $100 \%$, targeting flow rate of $\geq 50 \mathrm{~L} / \mathrm{min}$ with an inspiratory rise time of $50 \mathrm{msec}$ and end flow/cycling off of $50 \%$ of maximal inspiratory flow. PEEP may be increased by $2 \mathrm{~cm}$ every 3 minutes to achieve oxygen saturation (SpO2) $\geq 90 \%$ on $\mathrm{FIO}_{2} \leq 60 \%$, and $\mathrm{PS}$ can be increased by $2 \mathrm{~cm}$ every 3 minutes to achieve respiratory rate $\leq 25 / \mathrm{min}$ and disappearance of accessory muscle activity. The maximal allowed PS + PEEP is $30 \mathrm{~cm} \mathrm{H}_{2} \mathrm{O}$. Interruptions of helmet should be avoided or kept at minimum at least in the first 48 hours. ${ }^{20}$ More details of helmet NIV application, set up and weaning can be found in the Supplementary File. Some patients may not tolerate helmet NIV. In that case, the physician or the respiratory therapist explains the procedure to the patient. Dexmedetomidine infusion may be used to improve ccomfort with the helmet NIV. Other intravenous sedatives such as benzodiazepines or intravenous narcotics should generally not be used. If the patient continues to be intolerant to the helmet, the patient can be managed according to the usual care. Detailed data about helmet NIV tolerance are collected. 


\section{Control group}

In the control group, patients receive usual care according to the clinical practices of each site. This may include oxygen provided using standard oxygen devices, high-flow nasal oxygen or NIV provided by nasal mask, face mask or total mask.

\section{Endotracheal Intubation}

The decision to intubate will be at the discretion of the treating team with no involvement from the research team. However, the protocol provides guidance on assessing patients for the need of endotracheal intubation throughout the study period (for both study groups:

helmet NIV or usual care) according to the following general principles:

Enrolled patients should be assessed within 4 hours of enrollment (or sooner as required) and at frequent intervals for the following criteria, although the decision is usually not based on a single variable:

- Neurologic deterioration (not attributed to sedation)

- Persistent or worsening respiratory failure of NIV (manifesting as oxygen saturation $<88 \%$, respiratory rate $>36 / \mathrm{min}, \mathrm{PaO}_{2} / \mathrm{FiO}_{2}$ ratio $<100$ or persistent requirement of $\mathrm{FiO}_{2} \geq 70 \%$ )

- Intolerance of face mask or helmet

- Airway bleeding

- Copious respiratory secretions

- Respiratory acidosis with $\mathrm{pH}<7.25$

- Hemodynamic instability

- Significant radiologic worsening 


\section{Co-Interventions}

Patients who require endotracheal intubation are managed by the primary team with lung protective strategy with tidal volumes of $6 \mathrm{~mL} / \mathrm{kg}$ of predicted body weight and titration of PEEP to achieve oxygen saturation of $88 \%$ to $95 \%$ at the lowest possible $\mathrm{FiO}_{2}$. Daily interruption of sedation, awakening and breathing trials, and early mobilization are performed as per the ICU standards. ${ }^{25}$ Management of COVID-19 is provided as per local protocols; physicians are advised to follow the clinical practice guidelines set by the Saudi Critical Care Society, ${ }^{26}$ the Surviving Sepsis Campaign, ${ }^{27} 28$ and the World Health Organization. ${ }^{29}$ The study protocol does not mandate particular therapies; however, corticosteroids, immune modulators and antiviral therapy are all recorded. Conservative fluid management is recommended where neutral balance should be targeted and intravenous resuscitation should be reserved for shock treatment in both groups and fluid balance is recorded.

\section{Blinding}

Due to the nature of the study intervention, blinding is not be possible.

\section{Recruitment schedule and enrollment procedures}

Schedule of assessments is detailed in Table 2. All non-intubated subjects with suspected or confirmed COVID-19 are screened upon admission to the ICU. A screening log will be kept to monitor and report the size of the patient population from which eligible patients have been randomized. Co-enrollment in other RCTs is permissible as long as inclusion in the other RCT would not confound the results of this trial and after discussion with the steering committees of the other studies. 


\section{Data collection}

Baseline data on demographics, admission diagnosis and clinical information are collected. Clinical information include Acute Physiology and Chronic Health Evaluation (APACHE) II score ${ }^{30}$ source of admission, ICU admission category (elective, emergency or non-surgical), ICU admission diagnosis and co-morbidities (as defined by the APACHE II severity of illness scoring system). Daily data will be recorded until discharge from ICU or 28 days after randomization. We will collect data on the use of helmet including the tolerance of helmet (>1-hour use).

\section{Outcomes}

The primary outcome is 28-day all-cause mortality. Secondary outcomes are intubation rate within 28 days, ICU mortality, hospital mortality (censored at day 180), ICU-free days at day 28 , invasive ventilation-free days at day 28 , renal replacement therapy-free days at day 28 and vasopressor-free days at day 28. Safety outcomes include skin pressure injuries, barotrauma and serious adverse events (including cardiovascular events and device complications).

Additionally, there will be a follow up of enrolled patients at day 180 about vital status, functional status (EuroQoL (EQ)-5D-5L) which is planned to be reported separately. For patients who have been discharged from hospital before day 180 , follow up will be conducted by telephone.

\section{Data analysis}

A formal statistical analysis plan will be agreed upon and placed in the public domain before the study database is locked for the analysis of the primary outcome. The primary outcome 
will be compared in the intention-to-treat and per-protocol cohorts (effectiveness analysis) using the chi-square test. Results will be reported as relative risk with $95 \% \mathrm{Cl}$. Kaplan-Meier curves will be plotted to assess the time from enrollment to death and will be compared by means of the log-rank test. A two-tailed $P$ value $<0.05$ will be considered to indicate statistical significance. SAS software, version 9.2 (SAS Institute) will be used for all the analyses.

A priori analysis will be done for the following subgroups:

I. Patients with moderate $\mathrm{ARDS}\left(\mathrm{PaO}_{2} / \mathrm{FIO}_{2}\right.$ ratio $\left.100-200\right)$ and patients with severe ARDS $\left(\mathrm{PaO}_{2} / \mathrm{FIO} 2\right.$ ratio $\left.<100\right)$

II. Obese patients (body mass index $>30 \mathrm{~kg} / \mathrm{m}^{2}$ ) and patients with body mass index $\leq 30$

III. Patients aged $>65$ years and $\leq 65$ years

IV. APACHE II score higher or lower than the median of enrolled patients

For the occasional randomized patient who is withdrawn from the trial and allows use of data, the patient's data will be included in the group to which he/she was allocated as per the intention-to-treat principle and the reason of withdrawal will be documented.

\section{Trial management and monitoring}

The study Steering Committee members will be responsible for overseeing the conduct of the trial, for upholding or modifying study procedures as needed, addressing challenges with protocol implementation, formulating the analysis plan, reviewing and interpreting the data, and preparing the manuscript. This will be achieved through meetings (in-person or by conference calls) at least quarterly.

Several measures are taken to minimize, observe and document any potential safety concerns. First, any unexpected safety concerns will be reported immediately to the Steering 
Committee and IRB. Second, an independent Data Safety Monitoring Board will be monitoring the safety of the trial. Lastly, interim analyses will be conducted after recruiting $1 / 3$ and $2 / 3$ of the total patients and the interim test statistics will be the primary outcome analysis for both safety and effectiveness. The Data Safety Monitoring Board will use formal stopping rules based on the primary endpoint of 28 -day mortality. The trial may be stopped for safety $(p<0.01)$ or effectiveness $(p<0.001)$. There will be no plans to terminate the trial for futility. We will account for alpha spending by the O'Brien Fleming method and the final $p$ value will be considered at 0.048 . The principles used in the conduct of safety monitoring and reporting in this trial are those outlined by Cook et al. ${ }^{32}$

In this trial, reporting of serious adverse events will be restricted to events that are not captured as study outcome and are considered to be related to the helmet NIV (possibly, probably or definitely). ${ }^{32}$ These may include cardiovascular events (i.e., cardiac arrest and hypotension with drop in blood pressure to systolic $<90 \mathrm{~mm} \mathrm{Hg}$ ) and device complications (i.e., helmet deflation).

\section{Ethics and dissemination}

The study will be conducted according to the principles of the latest version of Good Clinical Practice (GCP) and in accordance with all relevant local ethical, regulatory, and legal requirements. A manuscript with the results of the primary study will be published in a peerreviewed journal. Separate manuscripts will be written on secondary aims, and these will also be submitted for publication in peer reviewed journals as well.

\section{Discussion}

The importance of this study stems from the current pandemic situation as different treatment modalities are being sought to answer important clinical questions. Available 
literature on the evaluation of helmet NIV as a respiratory support modality in COVID-19 patients is limited. Table 3 provides the list of ongoing RCTs on helmet NIV. This study aims to contribute to the existing literature and in turn influence clinical practice.

We planned our pragmatic trial to address whether using helmet NIV as the primary noninvasive respiratory support in patients with severe COVID-19, in addition to the commonly used high-flow nasal oxygen and mask NIV improves outcome. By nature of this question, there is heterogeneity of the control group; as patients in this group could receive standard oxygen, high-flow nasal oxygen or mask NIV at the decision of the treating team. This approach is supported by a recent network meta-analysis of randomized controlled trials that showed only a modest effect of high-flow nasal oxygen and mask NIV on mortality or intubation rate compared to standard oxygen, while patients treated with helmet NIV had more than $50 \%$ reduction in mortality and intubation rate compared to the other three modalities. ${ }^{18}$ In addition, this approach is likely to be more representative of usual practice in which patients may get oxygen therapy, high-flow nasal oxygen and NIV at different times during their acute illness. Given the fact that the use of helmet NIV has not been widespread across ICUs, we thought that the broader question addressed by our study might be more relevant to deciding whether to introduce this modality or not in a given ICU.

The main limitation to our study is inability to blind the given allocation due to the nature of the intervention. 


\section{REFERENCES}

1. World Health Organization. https://covid19.who.int/ Accessed on March 29, 2021.

2. Marini J, Gattinoni L. Management of COVID-19 Respiratory Distress. Jama 2020

3. Guan W-j, Ni Z-y, Hu Y, et al. Clinical Characteristics of Coronavirus Disease 2019 in China. New England Journal of Medicine 2020;382(18):1708-20. doi:

10.1056/NEJMoa2002032

4. Ñamendys-Silva SA. Respiratory support for patients with COVID-19 infection. The Lancet Respiratory medicine 2020;8(4):e18.

5. Richardson S, Hirsch JS, Narasimhan M, et al. Presenting Characteristics, Comorbidities, and Outcomes Among 5700 Patients Hospitalized With COVID-19 in the New York City Area. Jama

6. Xu X, Zhang X, Hu S, et al. Noninvasive Ventilation in Acute Hypoxemic Nonhypercapnic Respiratory Failure: A Systematic Review and Meta-Analysis, 2017.

7. Brambilla AM, Aliberti S, Prina E, et al. Helmet CPAP vs. oxygen therapy in severe hypoxemic respiratory failure due to pneumonia. Intensive Care Med 2014;40(7):9429. doi: 10.1007/s00134-014-3325-5 [published Online First: 2014/05/13]

8. Arulkumaran N, Brealey D, Howell D, et al. Use of non-invasive ventilation for patients with COVID-19: a cause for concern? The Lancet Respiratory medicine 2020 doi: 10.1016/S2213-2600(20)30181-8

9. Rodriguez AME, Papadakos PJ, Carron M, et al. Clinical review: Helmet and noninvasive mechanical ventilation in critically ill patients. Critical Care 2013;17(2):223.

10. Patroniti N, Foti G, Manfio A, et al. Head helmet versus face mask for non-invasive continuous positive airway pressure: a physiological study. Intensive care medicine 2003;29(10):1680.

11. Cosentini R, Brambilla AM, Aliberti S, et al. Helmet continuous positive airway pressure vs oxygen therapy to improve oxygenation in community-acquired pneumonia: a randomized, controlled trial. Chest 2010;138(1):114-20. doi: 10.1378/chest.09-2290 [published Online First: 2010/02/16]

12. Patel BK, Wolfe KS, Pohlman AS, et al. Effect of Noninvasive Ventilation Delivered by Helmet vs Face Mask on the Rate of Endotracheal Intubation in Patients With Acute Respiratory Distress Syndrome: A Randomized Clinical Trial. JAMA 2016;315(22):2435.

13. Foti G, Sangalli F, Berra L, et al. Is helmet CPAP first line pre-hospital treatment of presumed severe acute pulmonary edema? Intensive care medicine 2009;35(4):656. 
medRxiv preprint doi: https://doi.org/10.1101/2021.08.04.21260420; this version posted August 6, 2021. The copyright holder for this preprint (which was not certified by peer review) is the author/funder, who has granted medRxiv a license to display the preprint in perpetuity.

All rights reserved. No reuse allowed without permission.

14. Squadrone V, Coha M, Cerutti E, et al. Continuous positive airway pressure for treatment of postoperative hypoxemia: a randomized controlled trial. Jama 2005;293(5):589.

15. Patel BK, Wolfe KS, MacKenzie E, et al. One Year Outcomes in Patients with Acute Respiratory Distress Syndrome Enrolled in a Randomized Clinical Trial of Helmet versus Facemask Noninvasive Ventilation. Critical care medicine 2018;46(7):1078.

16. Liu Q, Gao Y, Chen R, et al. Noninvasive ventilation with helmet versus control strategy in patients with acute respiratory failure: a systematic review and metaanalysis of controlled studies. Critical Care 2016;20(1)

17. Luo Y, Luo Y, Li Y, et al. Helmet CPAP versus Oxygen Therapy in Hypoxemic Acute Respiratory Failure: A Meta-Analysis of Randomized Controlled Trials, 2016.

18. Ferreyro BL, Angriman F, Munshi L, et al. Association of Noninvasive Oxygenation Strategies With All-Cause Mortality in Adults With Acute Hypoxemic Respiratory Failure: A Systematic Review and Meta-analysis. Jama 2020;324(1):57-67. doi: 10.1001/jama.2020.9524

19. Kyeremanteng K, Gagnon LP, Robidoux R, et al. Cost Analysis of Noninvasive Helmet Ventilation Compared with Use of Noninvasive Face Mask in ARDS. Can Respir J 2018;2018:6518572. doi: 10.1155/2018/6518572 [published Online First: 2018/04/20]

20. Grieco DL, Menga LS, Cesarano M, et al. Effect of Helmet Noninvasive Ventilation vs High-Flow Nasal Oxygen on Days Free of Respiratory Support in Patients With COVID-19 and Moderate to Severe Hypoxemic Respiratory Failure: The HENIVOT Randomized Clinical Trial. Jama 2021 doi: 10.1001/jama.2021.4682

21. Bellani G, Laffey J, Pham T, et al. Epidemiology, Patterns of Care, and Mortality for Patients With Acute Respiratory Distress Syndrome in Intensive Care Units in 50 Countries. Jama 2016;315(8):788.

22. Hasan SS, Capstick T, Ahmed R, et al. Mortality in COVID-19 patients with acute respiratory distress syndrome and corticosteroids use: a systematic review and metaanalysis. Expert Rev Respir Med 2020;14(11):1149-63. doi:

10.1080/17476348.2020.1804365 [published Online First: 2020/08/01]

23. Sample Size Calculator. https://clincalc.com/stats/samplesize.aspx.

24. Centers for Disease Control and Prevention. Coronavirus Disease 2019 (COVID-19). 2020 Interim Case Definition, Approved April 5, 2020.

https://wwwn.cdc.gov/nndss/conditions/coronavirus-disease-2019-covid-19/casedefinition/2020/. Accessed on June 2, 2020.

25. Arabi Y, Al Aseri Z, Alaama T, et al. National Approach to Standardize and Improve Mechanical Ventilation. Annals of thoracic medicine 2019;14(2):101. 
26. Alhazzani W, Al-Suwaidan F, Al Aseri Z, et al. The saudi critical care society clinical practice guidelines on the management of COVID-19 patients in the intensive care unit. Saudi Critical Care Journal 2020;4(2):27-44. doi: 10.4103/sccj.sccj_15_20

27. Alhazzani W, Evans L, Alshamsi F, et al. Surviving Sepsis Campaign Guidelines on the Management of Adults With Coronavirus Disease 2019 (COVID-19) in the ICU: First Update. Critical Care Medicine 2021;49(3):e219-e34. doi: $10.1097 / \mathrm{ccm} .0000000000004899$

28. Alhazzani W, Møller MH, Arabi YM, et al. Surviving Sepsis Campaign: Guidelines on the Management of Critically III Adults with Coronavirus Disease 2019 (COVID-19). Critical Care Medicine 2020;48(6):e440-e69. doi: 10.1097/ccm.0000000000004363

29. Coronavirus disease (COVID-19) technical guidance: Patient management. https://www.who.int/emergencies/diseases/novel-coronavirus-2019/technicalguidance/patient-management. Accessed 1 March 2021.

30. Knaus WA, Draper EA, Wagner DP, et al. APACHE II: a severity of disease classification system. Crit Care Med 1985;13(10):818-29. [published Online First: 1985/10/01]

31. Herdman M, Gudex C, Lloyd A, et al. Development and preliminary testing of the new five-level version of EQ-5D (EQ-5D-5L). Quality of life research 2011;20(10):1727-36.

32. Cook D, Lauzier F, Rocha MG, et al. Serious adverse events in academic critical care research. CMAJ : Canadian Medical Association journal = journal de I'Association medicale canadienne 2008;178(9):1181-84. 


\section{Acknowledgements}

The authors would like to thank all the participating patients and their families, as well as the members of the Data Safety \& Monitoring Board: Chair: Dr. Nicholas S. Hill (Professor of Medicine, Chief of Pulmonary, Critical Care and Sleep Division, Tufts Medical Center, Boston, Massachusetts, USA), DSM members: Dr. Stefano Nava (Professor of Respiratory Medicine University of Bologna, Chief of the Respiratory and Critical Care Sant' Orsola Hospital Bologna, Specialist in Respiratory Medicine and Intensive Care Medicine, University of Bologna, Italy), Dr. James Mojica (Vice Chief and Clinical Director of Pulmonary \& Critical Care, Director, The Sleep Center at Spaulding, Massachusetts General Hospital, USA) and Dr. Michael Harhay (Assistant Professor of Epidemiology and Medicine-Pulmonary and Critical Care, Department of Biostatistics, Epidemiology and Informatics, University of Pennsylvania USA).

Contributors YA is the principal investigator and participated in the project concept, design, final approval, and manuscript preparation, review and submission. HT, SD, HD, SA, MH, $\mathrm{HH}, \mathrm{MM}, \mathrm{OZ}, \mathrm{EQ}, \mathrm{WW}, \mathrm{SQ}, \mathrm{FH}, \mathrm{JC}, \mathrm{MS}, \mathrm{AH}, \mathrm{AM}, \mathrm{AE}, \mathrm{AB}, \mathrm{ZA}, \mathrm{ZD}, \mathrm{AK}, \mathrm{RQ}, \mathrm{AG}, \mathrm{AT}, \mathrm{KG}$, MA, HG, AA, FB, HS, MO, YI, AF participated in the critical revision, final approval of the protocol and manuscript preparation, review and submission. All authors agree to be accountable for the accuracy and integrity of the work.

Funding The study is funded by King Abdullah International Medical Research Center (RC $20 / 306 / R)$. The study sponsor does not have any role in the study design, collection, management, analysis, and interpretation of data as well as writing of the report.

\section{Competing interests None declared}

\section{Ethics approval}

The study has been approved by the Institutional Review Board (IRB) of Ministry of National Guard Health Affairs (MNGHA) and the respective Institutional Review Boards of all the other centers.

Patient consent for publication Not required.

Provenance and peer review Not commissioned, externally peer reviewed. 
Table 1. Eligibility Criteria

\begin{tabular}{|c|c|}
\hline $\begin{array}{l}\text { Inclusion } \\
\text { Criteria }\end{array}$ & $\begin{array}{l}\text { 1. Suspected or confirmed COVID-19* } \\
\text { 2. Aged } \geq 14 \text { years old. ICUs that use other age cut-off for adult patients will adhere to their local standard ( } 16 \text { or } 18 \text { years) } \\
\text { 3. Acute hypoxemic respiratory failure based on } \mathrm{PaO} 2 / \mathrm{FiO} 2 \text { ratio }<200 \text { despite supplemental oxygen with a partial or non- } \\
\text { rebreathing mask at a flow rate }>10 \mathrm{~L} / \mathrm{min} \text { or above } \\
\text { 4. Intact airway protective gag reflex } \\
\text { 5. Able to follow instructions }\end{array}$ \\
\hline $\begin{array}{l}\text { Exclusion } \\
\text { Criteria }\end{array}$ & $\begin{array}{l}\text { 1. Prior intubation during this hospital admission } \\
\text { 2. Cardiopulmonary arrest } \\
\text { 3. Glasgow coma scale }<12 \\
\text { 4. Tracheostomy } \\
\text { 5. Upper airway obstruction } \\
\text { 6. Active epistaxis } \\
\text { 7. Requirement for more than one vasopressor to maintain mean arterial pressure }>65 \mathrm{~mm} \mathrm{Hg} \text {. } \\
\text { 8. Pregnancy } \\
\text { 9. Imminent intubation } \\
\text { 10. Patients with do-not-intubate orders (or equivalent) } \\
\text { 11. Enrolled in another trial for which co-enrolment is not approved including trials on mechanical ventilation } \\
\text { 12. Patients already treated with helmet } \\
\text { 13. Patients with chronic carbon dioxide retention (PaCO2>45) } \\
\text { 14. Previous enrolment in this trial } \\
\text { 15. The primary cause of respiratory failure is not heart failure as judged by the treating team }\end{array}$ \\
\hline $\begin{array}{l}\text { Eligible non- } \\
\text { randomized }\end{array}$ & $\begin{array}{l}\text { 1. Patient or substitute decision-maker declines consent } \\
\text { 2. ICU physician or other treating clinician declines consent }\end{array}$ \\
\hline
\end{tabular}

*A suspected/probable COVID-19 case is defined as: At least two of the following symptoms: fever (measured or subjective), chills, rigors, myalgia, headache, sore throat, new olfactory and taste disorder(s) OR at least one of the following symptoms: cough, shortness of breath, or difficulty breathing OR severe respiratory illness with at least one of the following: Clinical or radiographic evidence of pneumonia, OR ARDS AND no alternative more likely diagnosis. A confirmed COVID-19 case is defined as: Detection of SARS-CoV-2 RNA in a respiratory specimen using a molecular amplification detection test such as rt-PCR (https://wwwn.cdc.gov/nndss/conditions/coronavirus-disease-2019-covid-19/case-definition/2020/). 
Table 2. Schedule of assessments in the trial

\begin{tabular}{|l|c|c|c|c|}
\hline Task & Screening & Randomization & Baseline & Day 1-28 \\
& & & \\
Follow up \\
\hline Assess eligibility to enter study & $\mathrm{X}$ & & & \\
\hline Assess ability to gain consent \& follow-up & $\mathrm{X}$ & & & \\
\hline Consent & $\mathrm{X}$ & & & \\
\hline Demographics and eligibility checklist & $\mathrm{X}$ & $\mathrm{X}$ & $\mathrm{X}$ \\
\hline Laboratory data & & & $\mathrm{X}$ & \\
\hline Vital signs & & & $\mathrm{X}$ & \\
\hline Vital status up to Day 28 in the ICU & & & $\mathrm{X}$ \\
\hline Vital and functional status & & & $\mathrm{X}$ \\
\hline Discharge date from ICU, from hospital & & & $\mathrm{X}$ \\
\hline Adverse events & & & $\mathrm{X}$ \\
\hline Protocol violations & & & $\mathrm{X}$ \\
\hline
\end{tabular}


Table 3. List of ongoing registered randomized controlled trials (RCTs) on helmet noninvasive ventilation

\begin{tabular}{|c|c|c|c|c|c|}
\hline Trial & Registration & Interventions & Design & Countries & $\mathbf{N}$ \\
\hline $\begin{array}{l}\text { Helmet non-invasive ventilation for COVID- } \\
19 \text { patients (Helmet-COVID) }\end{array}$ & NCT04477668 & Helmet vs. usual care & Multicenter RCT & Saudi Arabia & 320 \\
\hline $\begin{array}{l}\text { Comparison of high-flow nasal oxygen, } \\
\text { face-mask NIV and helmet NIV in COVID- } \\
19 \text { ARDS patients (NIV COVID19) }\end{array}$ & NCT04715243 & $\begin{array}{l}\text { High-flow nasal oxygen vs. } \\
\text { helmet NIV vs. mask NIV }\end{array}$ & Multicenter RCT & Oman & 360 \\
\hline $\begin{array}{l}\text { Helmet CPAP vs. high-flow nasal oxygen } \\
\text { in COVID-19 (COVID HELMET) }\end{array}$ & NCT04395807 & $\begin{array}{l}\text { High-flow nasal oxygen vs. } \\
\text { helmet CPAP }\end{array}$ & Single-center RCT & Sweden & 120 \\
\hline $\begin{array}{l}\text { high-flow nasal oxygen vs. CPAP Helmet } \\
\text { in COVID-19 pneumonia (COVIDNOCHE) }\end{array}$ & NCT04381923 & $\begin{array}{l}\text { High-flow nasal oxygen vs. } \\
\text { helmet CPAP }\end{array}$ & Single-center RCT & USA & 200 \\
\hline $\begin{array}{l}\text { Early CPAP in COVID-19 patients with } \\
\text { respiratory failure (EC-COVID-RCT) }\end{array}$ & NCT04326075 & $\begin{array}{c}\text { Early helmet CPAP vs. } \\
\text { usual care }\end{array}$ & Single-center RCT & Italy & 900 \\
\hline
\end{tabular}

